\title{
Erratum: Sharpening of directional selectivity from neural output of rabbit retina
}

\author{
Aurel Vasile Martiniuc • Günther Zeck • \\ Wolfgang Stürzl • Alois Knoll
}

Published online: 2 December 2010

(C) Springer Science+Business Media, LLC 2010

\section{Erratum to: J Comput Neurosci}

\section{DOI 10.1007/s10827-010-0266-z}

The author group of this article should be as follows:

Aurel Vasile Martiniuc

Günther Zeck

Wolfgang Stürzl

Alois Knoll

The online version of the original article can be found at http://dx.doi. org/10.1007/s10827-010-0266-z.

A. V. Martiniuc $(\bowtie) \cdot$ A. Knoll

Computer Science Department VI, Technical University Munich,

85748 Garching, Germany

e-mail: martiniv@in.tum.de

A. Knoll

e-mail: knoll@in.tum.de

G. Zeck

Department of Systems and Computational Neuroscience,

Max Planck Institute of Neurobiology,

82152 Martinsried, Germany

e-mail: zeck@neuro.mpg.de

W. Stürzl

Department of Neurobiology, Center of Excellence

'Cognitive Interaction Technology', Bielefeld University,

33501 Bielefeld, Germany

e-mail: wolfgang.stuerzl@uni-bielefeld.de 